\title{
Electron Detachment Dissociation of Dermatan Sulfate Oligosaccharides
}

\author{
Jeremy J. Wolff, Tatiana N. Laremore, ${ }^{\mathrm{b}}$ Alexander M. Busch, \\ Robert J. Linhardt, ${ }^{\mathrm{b}, \mathrm{c}, \mathrm{d}}$ and I. Jonathan Amster ${ }^{\mathrm{a}}$ \\ ${ }^{a}$ Department of Chemistry, University of Georgia, Athens, Georgia, USA \\ ${ }^{\mathrm{b}}$ Department of Chemistry and Chemical Biology, Rensselaer Polytechnic Institute, Troy, New York, USA \\ ${ }^{c}$ Department of Chemical and Biological Engineering, Rensselaer Polytechnic Institute, Troy, New York, USA \\ d Department of Biology, Rensselaer Polytechnic Institute, Troy, New York, USA
}

The structural characterization of glycosaminoglycans (GAG) oligosaccharides has been a long-standing challenge in the field of mass spectrometry. In this work, we present the application of electron detachment dissociation (EDD) Fourier transform mass spectrometry to the analysis of dermatan sulfate (DS) oligosaccharides up to 10 residues long. The EDD mass spectra of DS oligosaccharides were compared with their infrared multiphoton dissociation (IRMPD) mass spectra. EDD produces more abundant fragmentation than IRMPD with far less loss of $\mathrm{SO}_{3}$ from labile sulfate modifications. EDD cleaves all glycosidic bonds, yielding both conventional glycosidic bond fragmentation as well as satellite peaks resulting from the additional loss of 1 or 2 hydrogen atoms. EDD also yields more cross-ring fragmentation than IRMPD. For EDD, abundant cross-ring fragmentation in the form of A- and X-ions is observed, with ${ }^{1,5} \mathrm{X}_{n}$ cleavages occurring for all IdoA residues and many of the GalNAc4S residues, except at the reducing and nonreducing ends. In contrast, IRMPD produces only A-type cross-ring fragmentation for long oligosaccharides $(\mathrm{dp} 6-\mathrm{dp} 10)$. As all the structurally informative fragment ions observed by IRMPD appear as a subset of the peaks found in the EDD mass spectrum, EDD shows great potential for the characterization of GAG oligosaccharides using a single tandem mass spectrometry experiment. (J Am Soc Mass Spectrom 2008, 19, 294-304) @ 2008 American Society for Mass Spectrometry

G lycosaminoglycans (GAGs) are linear polysaccharides that comprise the carbohydrate portion of many proteoglycans and are found in a variety of organisms ranging from bacteria to humans [1]. GAGs participate in a number of important biological activities, such as binding growth factors and chemokines [2, 3], inhibiting proteolysis [4], affecting angiogenesis [5], and acting as signaling molecules in response to cellular damage [6]. GAGs also play an important role in pathogenic infections [7-9], and have been shown to undergo alteration in certain types of cancer [10]. GAGs are assigned to one of four classes: heparin and heparan sulfate (HS), dermatan sulfate (DS) and chondroitin sulfate (CS), hyaluronic acid, and keratan sulfate (KS) [11]. With the exception of KS, GAGs are composed of alternating uronic acid and hexosamine residues with variable degrees of sulfation and $\mathrm{N}$-acetylation. KS is composed of a hexosehexosamine disaccharide repeat. There is significant interest in determining the pattern of sulfation, Nacetylation of basic residues, and C5 epimerization of the acidic residues, as these modifications are believed to determine the biological activity of the GAG chain. One- and two-dimensional NMR have been used to

Address reprint requests to Dr. I. J. Amster, Department of Chemistry, University of Georgia, Athens, GA 30602, USA. E-mail: jamster@uga.edu determine the type and location of GAG modification [12], as well as the stereochemistry of C5 on hexuronic acid, but NMR analysis requires milligram quantities of a high purity sample. As GAGs must be isolated from natural sources, they are often available only in low quantity and purity, and there is considerable interest in the development of more sensitive methods for structural analysis of GAGs.

Mass spectrometry (MS) and tandem mass spectrometry (MS/MS) are viable alternatives for the structural analysis of GAGs as they require small quantities of sample and can be used to examine complex mixtures. Progress in the development of MS methods of GAG analysis has been slow compared with protein analysis due to the anionic nature of GAGs and the lability of sulfate as a carbohydrate modification. Electrospray ionization (ESI) [13] and matrix assisted laser desorption ionization (MALDI) [14-17] have been used to ionize sulfated GAGs in intact form. However, MS/MS of sulfated GAGs often leads to loss of $\mathrm{SO}_{3}$, obscuring the position of modification. A number of tandem mass spectrometry approaches have been developed to overcome these problems. Zaia and Costello have shown that $\mathrm{SO}_{3}$ loss can be minimized and glycosidic bond cleavages maximized by increasing the charge state of an ion so that the number of charges on the molecule is equal to the number of sulfates [18]. Their work also 
demonstrated that the addition of divalent calcium to sulfated GAGs decreased $\mathrm{SO}_{3}$ loss during MS/MS. Saad and Leary [19] demonstrated that a mixture of heparin/HS disaccharides can be characterized using ESI with tandem mass spectrometry to distinguish isobaric disaccharides. Using this method, the authors were able to determine the disaccharide composition of biological samples using only mass spectrometry. Short lengths of GAGs can be analyzed by a combination of enzymatic digestion, tandem mass spectrometry $\left(\mathrm{MS}^{2}\right.$ and $\left.\mathrm{MS}^{3}\right)$, and database searching [20]. While this approach can determine the pattern of modification (i.e., sulfation and acetylation), enzymatic digestion results in the formation of disaccharides containing $\mathrm{C} 4-\mathrm{C} 5$ unsaturated uronic acid ( $\triangle \mathrm{UA})$ at the nonreducing end (NRE), thereby converting glucuronic acid (GlcA) and iduronic acid (IdoA) into a single product ( $\Delta \mathrm{UA})$ that eliminates chirality at C5 [21]. As the epimeric state of the hexuronic acid residues is thought to influence biological activity, it is important to be able to analyze GAG oligosaccharides which contain internal hexuronic acid residues that retain their chirality. Although tandem mass spectrometry is typically insensitive to stereochemistry, MS/MS of a series of isobaric CS samples has been shown to distinguish IdoA from GlcA as well as distinguish $4 \mathrm{~S}$ - from $6 \mathrm{~S}$-sulfation based on the relative abundance of specific product ions [22].

We have recently reported the utility of electron detachment dissociation (EDD) [23-27] for the analysis of GAG HS tetrasaccharides [28, 29]. EDD produces a radical anion, which undergoes more extensive fragmentation than that produced from activation of even electron ions by low-energy or threshold dissociation methods. For HS tetrasaccharides, EDD produces both glycosidic bond and cross-ring fragmentation, revealing the sites of sulfation and acetylation, while minimizing $\mathrm{SO}_{3}$ loss. More recently, we demonstrated that EDD can distinguish the epimers IdoA from GlcA in HS tetrasaccharides [29]. While application of EDD to the characterization of HS tetrasaccharides appears very promising, the extension of this fragmentation technique to longer oligosaccharides remains an important goal. Many protein binding sites on GAGs are 3 to 9 disaccharides long, and GAG binding sites up to 15 disaccharides long have been reported [30-35]. ${ }^{\circ}$ Here $^{\circ}$ we demonstrate the applicability of EDD to the structural analysis of DS oligosaccharides up to 10 saccharides long.

\section{Materials and Methods}

\section{Preparation of DS Oligosaccharides}

Dermatan sulfate (DS) oligosaccharides were prepared by partial enzymatic depolymerization of porcine intestinal mucosa dermatan sulfate (Celsus Laboratories, Cincinnati, OH). A $20 \mathrm{mg} / \mathrm{mL}$ dermatan sulfate solution in $50 \mathrm{mM}$ Tris- $\mathrm{HCl} / 60 \mathrm{mM}$ sodium acetate buffer, pH 8 was incubated at $37^{\circ} \mathrm{C}$ with chondroitin $\mathrm{ABC}$
STRUCTURES

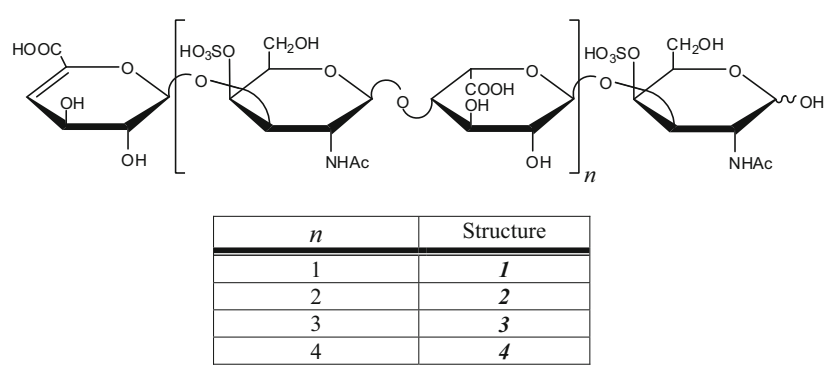

lyase from Proteus vulgaris, EC 4.2.2.4. (Seikagaku, Japan). After the absorbance at $232 \mathrm{~nm}$ indicated the digestion was $50 \%$ completed, the digestion mixture was heated at $100{ }^{\circ} \mathrm{C}$ for $3 \mathrm{~min}$. High molecular weight oligosaccharides and the enzyme were removed by ultrafiltration using a 5000 MWCO membrane. The resulting oligosaccharide mixture was concentrated by rotary evaporation and fractionated by low-pressure GPC on a Bio-Gel P10 (Bio-Rad, Richmond, CA) column. Fractions containing tetra- to decasaccharides (dp4 to dp10, Structures 1-4) were desalted by GPC on $\mathrm{a}^{\circ}$ Bio-Gel $^{\circ} \mathrm{P}^{\circ}{ }^{\circ}$ column $^{\circ}$ and $^{\circ}$ freeze-dried $^{\circ}[36] .{ }^{\circ}$ Further purification of Compounds 1-4 were carried out using strong anion exchange high-pressure liquid chromatography (SAX-HPLC) on a semi-preparative SAX S5 Spherisorb column (Waters Corp, Milford, MA). The SAX-HPLC fractions containing $>90 \%$ of $\mathbf{1 - 4}$ were collected, desalted by GPC, and freeze-dried. The solid was reconstituted in water and purified a second time by SAX-HPLC. Only the top 30\% of the chromatographic peak was collected, desalted, and freeze-dried. Concentration of the oligosaccharide solutions was determined by measuring the absorbance at $232 \mathrm{~nm}(\varepsilon=$ $3800 \mathrm{M}^{-1} \mathrm{~cm}^{-1}$ ). The resulting fractions containing the individual DS oligosaccharides, 1-4, were characterized by PAGE, ESI-MS, and high-field nuclear magnetic resonance (NMR) spectroscopy.

\section{Mass Spectrometry Analysis}

Experiments were performed with a 9.4 T Bruker Apex IV QeFTMS (Billerica, MA) fitted with an Apollo II dual source, a $25 \mathrm{~W} \mathrm{CO}_{2}$ laser (Synrad model J48-2; Mukilteo, WA) for infrared multiphoton dissociation (IRMPD), and an indirectly heated hollow cathode for generating electrons for ECD and EDD. Solutions of each oligosaccharide were introduced at a concentration of 0.1 to 0.2 $\mathrm{mg} / \mathrm{mL}$ in 50:50:0.1 methanol: $\mathrm{H}_{2} \mathrm{O}: \mathrm{NH}_{3}$ (Sigma, St. Louis, MO) and ionized by nanospray using a pulled fused silica tip (model FS360-75-15-D-20; New Objective, Woburn, MA). The sample solutions were infused at a rate of $10 \mu \mathrm{L} / \mathrm{h}$. All DS oligosaccharides, 1-4, were examined in negative ion mode. 


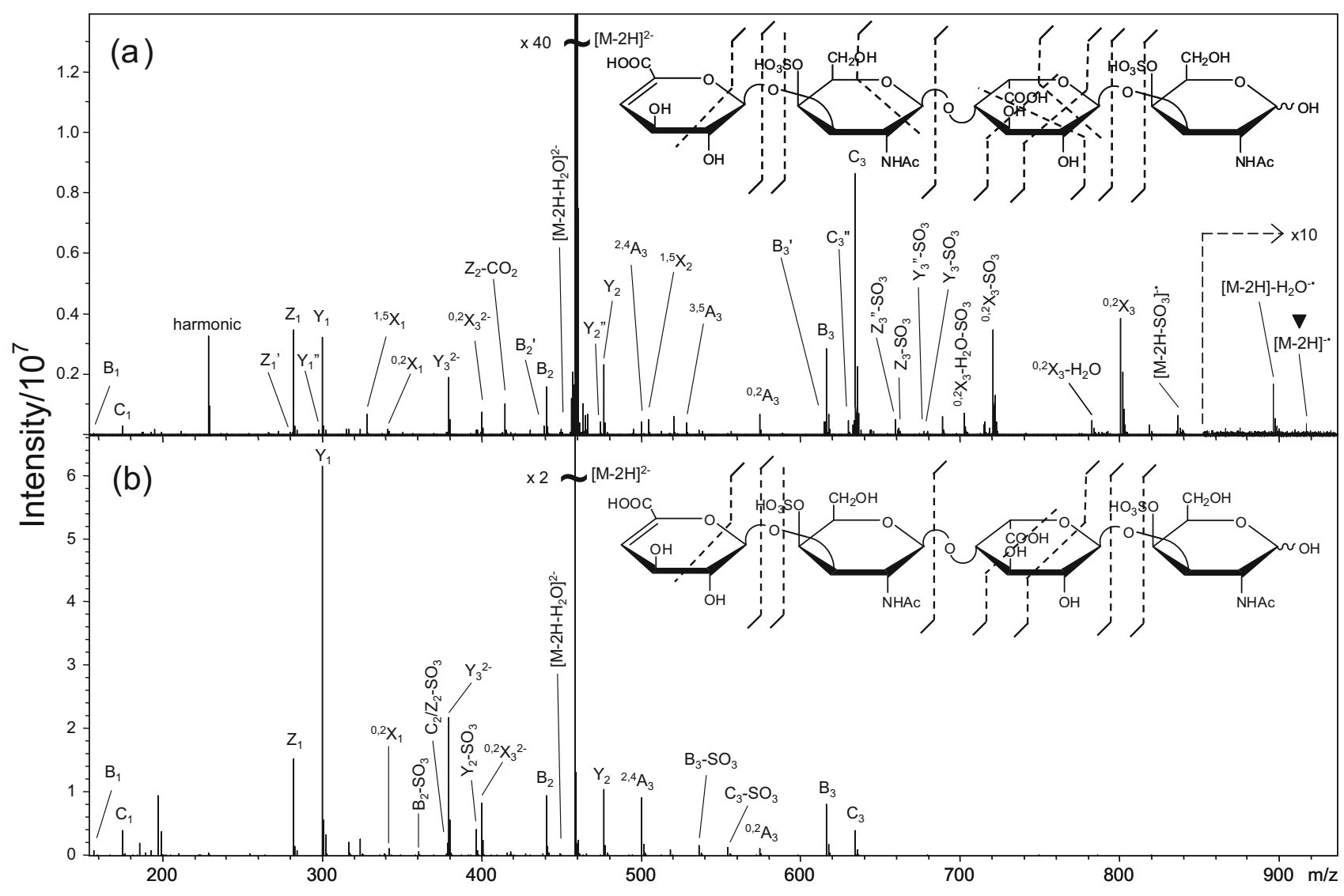

Figure 1. MS/MS of $[\mathrm{M}-2 \mathrm{H}]^{2-}$ precursor ion DS dp4, 1, with (a) EDD and (b) IRMPD. Insets: Product ions observed by the fragmentation methods. The charge reduced species in the EDD mass spectrum is indicated with an inverted filled triangle over the peak label.

For the EDD experiments, precursor ions were isolated in the external quadrupole and accumulated for 1 to $2 \mathrm{~s}$ before injection into the FTMS cell. The isolation/ cell fill was repeated up to six times. The selection of the precursor ion was further refined by using in-cell isolation with a coherent harmonic excitation frequency $(\mathrm{CHEF})^{\circ}$ event $^{\circ}[37] .{ }^{\circ}$ The $^{\circ}$ precursor ${ }^{\circ}$ ions ${ }^{\circ}$ were $^{\circ}$ then ${ }^{\circ}$ irradiated with electrons for $1 \mathrm{~s}$. For electron irradiation the cathode bias was set to $-19 \mathrm{~V}$, the extraction lens was set to $-17.5 \mathrm{~V} \pm 0.5 \mathrm{~V}$, and the cathode heater was set to 1.6 A. Twenty-four acquisitions were signal averaged per mass spectrum. For each mass spectrum, $512 \mathrm{~K}$ points were acquired, padded with one zero fill, and apodized using a sinebell window. Background spectra were acquired by leaving all parameters the same but setting the cathode bias to $0 \mathrm{~V}$ to ensure that no electrons reached the analyzer cell. IRMPD spectra were acquired using the same experimental setup as EDD, but replacing the electron irradiation event with a laser pulse. For IRMPD, ions were irradiated for 0.01 to $0.2 \mathrm{~s}$ beam attenuation set to pass from $40 \%$ to $60 \%$ of full power. External calibration of IRMPD and EDD mass spectra produced mass accuracy of $5 \mathrm{ppm}$. Internal calibration was also performed using confidently assigned glycosidic bond cleavage products as internal calibrants, providing mass accuracy of $<1 \mathrm{ppm}$. Due to the larger number of low intensity products formed by EDD, only peaks with $\mathrm{S} / \mathrm{N}>10$ are reported (see supplemental data, which can be found in the electronic version of this article). Product ions were assigned using accurate mass measurement. All EDD products are reported using the Domon and Costello nomenclature ${ }^{\circ}[38]$.

\section{${ }^{18} \mathrm{O}$ Labeling}

${ }^{18} \mathrm{O}$ labeling of the anomeric carbon of the reducing end was performed by dissolving $2 \mathrm{nmol}$ of the DS oligosaccharide into $10 \mu \mathrm{L}$ of $\mathrm{H}_{2}{ }^{18} \mathrm{O}$ (Cambridge Isotope Labs, Andover, MA). The solution was heated overnight at $60^{\circ} \mathrm{C}$. Before mass spectrometry analysis, $10 \mu \mathrm{L}$ of methanol was added to the $\mathrm{H}_{2}{ }^{18} \mathrm{O}$ oligosaccharide solution beforeinfusion into the'mass spectrometer [39].

\section{Results and Discussion}

\section{EDD of DS Tetrasaccharide (dp4)}

EDD of the $[\mathrm{M}-2 \mathrm{H}]^{2-}$ of DS dp4, 1, by irradiation with $19 \mathrm{eV}$ electrons produces the mass spectrum shown in Figure $^{\circ} 1 \mathrm{a},{ }^{\circ}$ while ${ }^{\circ} \mathrm{IRMPD}^{\circ}$ of $^{\circ}$ the ${ }^{\circ}\left[\mathrm{M}^{\circ}-{ }^{\circ} 2 \mathrm{H}\right]^{2-{ }^{\circ}}$ ion $^{\circ}$ of ${ }^{\circ} 1$ produces ${ }^{\circ}$ the ${ }^{\circ}$ mass $^{\circ}$ spectrum $^{\circ}$ shown $^{\circ}$ in $^{\circ}$ Figure $^{\circ} 1 \mathrm{~b} .{ }^{\circ} \mathrm{EDD}$ 
of 1 produces similar glycosidic bond cleavages to those observed in the IRMPD spectrum. However, more abundant cross-ring cleavages and less $\mathrm{SO}_{3}$ loss are observed ${ }^{\circ}$ in $^{\circ}$ EDD $^{\circ}$ of ${ }^{\circ} \mathbf{1}$ (insets, ${ }^{\circ}$ Figure $^{\circ} 1 a^{\circ}$ and $\left.{ }^{\circ} b\right)^{\circ}$ com- $^{-}$ pared with those produced by IRMPD. As observed with HS tetrasaccharides, the majority of cross-ring fragmentation resulting from EDD occurs in the residue bearing a carboxyl group, IdoA. As suggested previously, carboxylate readily undergoes electron detachment $^{\circ}[28]^{\circ}$ and $^{\circ}$ it $^{\circ}$ seems $^{\circ}$ reasonable $^{\circ}$ that ${ }^{\circ}$ this ${ }^{\circ}$ group $^{\circ}$ will become a radical site that will direct fragmentation to that residue.

The EDD mass spectrum of $\mathbf{1}$ contains predominantly singly-charged product ions and three doublycharged product ions, $\mathrm{Y}_{3}{ }^{2-},{ }^{0,2} \mathrm{X}_{3}{ }^{2-}$, and $[\mathrm{M}-2 \mathrm{H}-$ $\left.\mathrm{H}_{2} \mathrm{O}\right]^{2-} \cdot{ }^{\circ} \mathrm{As}^{\circ}$ described $^{\circ}$ previously $^{\circ}[28]^{\circ}$, the $^{\circ}$ doublycharged products show that some of the observed product ions result from activation of the precursor ion without electron detachment. These doubly-charged product ions result from fragmentation near the NRE of 1 and are also observed in the IRMPD mass spectrum of $1,{ }^{\circ}$ Figure $^{\circ} 1 b^{\circ}{ }^{\circ}$ For $^{\circ}$ this ${ }^{\circ}$ tetrasaccharide, ${ }^{\circ}$ cleavage $^{\circ}$ of $^{\circ}$ all glycosidic bonds is observed both by IRMPD and by EDD, except for the $Z_{3}$ glycosidic bond cleavage, which is observed only with loss of $\mathrm{SO}_{3}$, forming singlycharged, even-electron product ions $\mathrm{Z}_{3}-\mathrm{SO}_{3}$ and $\mathrm{Z}_{3}^{\prime \prime}-$ $\mathrm{SO}_{3}$ in the EDD mass spectrum of 1 . The $\mathrm{C}_{2}$ and $\mathrm{Z}_{2}$ glycosidic bond cleavages, if present, cannot be assigned as they overlap in mass-to-charge with the precursor ion. Cross-ring cleavages are observed both by EDD and IRMPD. However, IRMPD appears to produce fewer cross-ring fragments, and to favor the formation of A-type cross-ring fragments over X-type cross-ring fragments. The EDD mass spectrum shows considerably more cross-ring fragmentation, and X-ions are far more abundant than A-ions. It is important to note that all of the cross-ring fragments found by IRMPD also appear in the EDD spectrum.

Numerous odd-electron product ions are observed in the EDD mass spectrum of 1 . The charge reduced species $[\mathrm{M}-2 \mathrm{H}]^{--}$is observed at $m / z$ 916.125, albeit at low intensity, as well as the odd-electron product [M $\left.2 \mathrm{H}-\mathrm{SO}_{3}\right]^{--}$. Since sulfuric acid is more ionized than a carboxylic acid in solution, and since ESI is thought to preserve the ionized state of species as they move from solution to the gas phase, the doubly-charged anion of 1 is expected to carry each of its charges at a sulfate group. As the radical site formation is proposed to initially occur at a site of charge, EDD is expected to form a sulfate radical, which can readily undergo loss of $\mathrm{SO}_{3}$, consistent with the observation of the $[\mathrm{M}-2 \mathrm{H}-$ $\left.\mathrm{SO}_{3}\right]^{-\cdot}$ ion. However, the preponderance of cleavage on the ring with the carboxyl groups, IdoA, suggests the presence of a radical site on the uronic acid residue, even though it bears no sulfate. These data suggest radical site migration to the carboxyl group, most likely by hydrogen atom rearrangement. Alternatively, it is possible that the carboxyl group is a site of ionization in the doubly-charged precursor ion of 1, perhaps the result of proton migration. Detachment of an electron from a carboxylate anion is thermodynamically favorable, as it requires $\sim 1 \mathrm{eV}$ less energy than detachment of an electron from a sulfate anion, as noted previously [28]. ${ }^{\circ}$ Another ${ }^{\circ}$ explanation $^{\circ}$ for $^{\circ}$ the $^{\circ}$ abundance $^{\circ}$ of ${ }^{\circ} \operatorname{Ido}^{\circ}$ fragmentation is that EDD produces a hole in a molecular orbital, and that the hole migrates until it recombines ${ }^{\circ}$ with $^{\circ}$ an $^{\circ}$ electron ${ }^{\circ}{ }^{\circ}{ }^{\circ} \operatorname{IdoA}^{\circ}[24]$.

Another odd-electron ion of interest is the peak at $m / z$ 898.116, which differs from the charge-reduced species, $[\mathrm{M}-2 \mathrm{H}]^{-}$, by the exact mass of $\mathrm{H}_{2} \mathrm{O}$, and which is assigned as $\left[\mathrm{M}-2 \mathrm{H}-\mathrm{H}_{2} \mathrm{O}\right]^{-}$. This product is unusual as $\mathrm{H}_{2} \mathrm{O}$ loss from the charge-reduced species has not been observed previously in the EDD mass spectra $^{\circ}$ of $^{\circ} \mathrm{GAGs}^{\circ}\left[28,{ }^{\circ} 29\right] .{ }^{\circ} \mathrm{It}^{\circ}$ is $^{\circ}$ unlikely $^{\circ}$ that ${ }^{\circ}$ this $^{\circ}$ is ${ }^{\circ} \mathrm{a}$ secondary product ion resulting from the detachment of an electron from the $\left[\mathrm{M}-2 \mathrm{H}-\mathrm{H}_{2} \mathrm{O}\right]^{2-}$ product ion, given the low abundance of the $\left[\mathrm{M}-2 \mathrm{H}-\mathrm{H}_{2} \mathrm{O}\right]^{2-}$ product ion and the low efficiency of EDD fragmentation.

The peak at $m / z$ 800.111, assigned as the oddelectron product ${ }^{0,2} X_{3}$, is unusual in that it is observed as both a singly-charged odd-electron product ion $\left(\mathrm{m} / \mathrm{z} 800.111^{-.}\right)$and a doubly-charged even-electron product ion $\left(m / z 400.055^{2-}\right)$. The ${ }^{0,2} X_{3}$ product ion is isobaric with the ${ }^{2,5} \mathrm{~A}_{4}$ product ion, and to distinguish these we have performed ${ }^{18} \mathrm{O}$-labeling of the hydroxyl group at the anomeric position of the reducing end (RE). EDD of the ${ }^{18} \mathrm{O}$-labeled 1 (data not shown) caused both the singly- and doubly-charged ions to shift $+2 \mathrm{u}$, confirming that the products contain the reducing end of the GAG chain, consistent with the assignment of these as ${ }^{0,2} \boldsymbol{X}_{3}$ ions. The peak at $\mathrm{m} / \mathrm{z}$ 720.153 differs from the odd-electron ${ }^{0,2} X_{3}$ product by the exact mass of $\mathrm{SO}_{3}$, and is assigned as the oddelectron product ${ }^{0,2} \mathrm{X}_{3}-\mathrm{SO}_{3}{ }^{-}$.

The ${ }^{18} \mathrm{O}$-labeling of the reducing end of 1 allowed us to confirm the assignments of all the product ions. Those assigned as A, B, or C ions were found to undergo no mass shift upon labeling, while those assigned as $\mathrm{X}, \mathrm{Y}$, or $\mathrm{Z}$ all undergo a $+2 \mathrm{u}$ shift. One exception is the peak at $m / z 782.100$ which differs from the ${ }^{0,2} \mathrm{X}_{3}$ fragment by the exact mass of $\mathrm{H}_{2} \mathrm{O} \cdot{ }^{18} \mathrm{O}$ labeling was used to determine if this product was in fact the result of water loss from the ${ }^{0,2} X_{3}$ cleavage. The peak at $m / z 782.100 \mathrm{did}$ not shift $+2 \mathrm{u}$, indicating that this product either does not contain the reducing end (i.e., may not be an X-type ion), or that the resulting $\mathrm{H}_{2} \mathrm{O}$ loss removed the ${ }^{18} \mathrm{O}$ from the reducing end. Also, the product at $\mathrm{m} / \mathrm{z} 702.143$ differs from the peak at $\mathrm{m} / \mathrm{z}$ 782.100 by the exact mass of $\mathrm{SO}_{3}$, suggesting a composition of $\left[{ }^{0,2} \mathrm{X}_{3}-\mathrm{H}_{2} \mathrm{O}-\mathrm{SO}_{3}\right]^{-*}$. The peak at $m / z 702.143$ also did not shift $+2 \mathrm{u}$ with ${ }^{18} \mathrm{O}$-labeling, suggesting that either this product does not contain the reducing end, or that $\mathrm{H}_{2} \mathrm{O}$ loss removed the ${ }^{18} \mathrm{O}$ from the reducing end, resulting in a $\left[^{0,2} \mathrm{X}_{3}-\mathrm{H}_{2}{ }^{18} \mathrm{O}-\mathrm{SO}_{3}\right]^{-}$product ion. We are unable to assign these two product ions to any NRE fragmentation (i.e., A-type cleavage) or any internal fragment ion. 
In our prior work on HS tetrasaccharides, all products that result from IRMPD or CAD of sulfated GAGs are observed in the EDD mass spectrum. This is generally true for DS GAGs as well. The only product ions observed in IRMPD that are not observed in EDD are a small number that result from $\mathrm{SO}_{3}$ loss accompanying other fragmentation. In fact, very little $\mathrm{SO}_{3}$ loss is observed in the EDD mass spectrum of 1 . Aside from the $\left[\mathrm{M}-2 \mathrm{H}-\mathrm{SO}_{3}\right]^{--}$species, only one significant peak is observed to result from $\mathrm{SO}_{3}$ loss, namely ${ }^{0,2} \mathrm{X}_{3}-\mathrm{SO}_{3}$, which has the same abundance as the ${ }^{0,2} \mathrm{X}_{3}$ ion. A few low abundance product ions are found to result from $\mathrm{SO}_{3}$ loss $\left(\mathrm{Z}_{3}-\mathrm{SO}_{3}, \mathrm{Y}_{3}-\mathrm{SO}_{3}\right.$, and their $-2 \mathrm{H}$ counterparts), and no products are observed with loss of two $\mathrm{SO}_{3}$ molecules. The only product ion observed solely with $\mathrm{SO}_{3}$ loss is the $\left[\mathrm{Z}_{3}-\mathrm{SO}_{3}\right]^{-}$product. Compared to IRMPD of 1, far less $\mathrm{SO}_{3}$ loss is observed by EDD fragmentation ${ }^{\circ}\left(\right.$ Figure $\left.^{\circ} 1\right)$.

EDD of 1 results in numerous glycosidic bond cleavages that are accompanied by the loss of 1 or $2 \mathrm{H}$ atoms

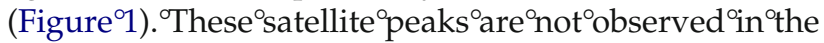
IRMPD mass spectrum of $\mathbf{1}$, suggesting that they arise from a radical site induced hydrogen rearrangement. Similar to EDD fragmentation previously observed in $\mathrm{HS}^{\circ}$ tetrasaccharides ${ }^{\circ}\left[28,{ }^{\circ} 29\right],{ }^{\circ}$ the ${ }^{\circ} \mathrm{B}_{3}$ glycosidic bond cleavage is accompanied by a $\mathrm{B}_{3}-\mathrm{H}$ product (labeled $\left.\mathrm{B}_{3}{ }^{\prime}\right)$, and the $\mathrm{C}_{3}$ glycosidic bond cleavage is accompanied by a $\mathrm{C}_{3}-2 \mathrm{H}$ product (labeled $\mathrm{C}_{3}{ }^{\prime \prime}$ ).

Previous studies of the EDD of HS tetrasaccharides found the formation of the ${ }^{0,2} \mathrm{~A}_{3}$ product occurred only for cross-ring cleavage of GlcA and not IdoA, and only

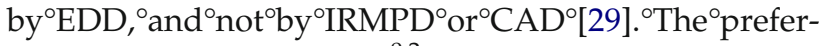
ence for the formation of ${ }^{0,2} \mathrm{~A}_{3}$ from GlcA versus IdoA was proposed to result from a radical mechanism involving an $\mathrm{H}$ atom rearrangement. Unlike $\mathrm{HS}$ tetrasaccharides, IRMPD of the DS tetrasaccharide 1 produces the ${ }^{0,2} \mathrm{~A}_{3}$ product ion. The mechanism of its formation is clearly different from EDD of HS tetrasaccharides as the ${ }^{0,2} \mathrm{~A}_{3}$ ion for $\mathbf{1}$ is produced from an even-electron ion. Furthermore, the ring undergoing fragmentation is IdoA, which does not produce ${ }^{0,2} \mathrm{~A}_{3}$ in EDD or IRMPD of HS. Given its formation from an even-electron precursor, the ${ }^{0,2} \mathrm{~A}_{3}$ fragment in the EDD spectrum is not expected to distinguish GlcA from IdoA in DS oligosaccharides.

To present a complete picture of the observed fragmentation, we propose an annotation scheme that can distinguish hydrogen transfer and $\mathrm{SO}_{3}$ loss in addition to the standard A, B, C, X, Y, and Z fragmentations. The $\mathrm{EDD}^{\circ}$ and ${ }^{\circ} \mathrm{IRMPD}{ }^{\circ}$ products ${ }^{\circ}$ for ${ }^{\circ} \boldsymbol{1}$ (insets, ${ }^{\circ}{ }^{\circ}$ Figure ${ }^{\circ} 1 \mathrm{a}^{\circ}$ and b) are combined in this new fragmentation annotation scheme, ${ }^{\circ}$ shown ${ }^{\circ}$ in $^{\circ}$ Figure $^{\circ} 2 .{ }^{\circ}$ This $^{\circ}$ scheme ${ }^{\circ}$ distinguishes products observed by IRMPD from those formed by $\mathrm{EDD}$ and can display additional hydrogen and $\mathrm{SO}_{3}$ loss. This scheme is particularly useful for examining the large number of fragment ions that are found in the mass spectra of longer oligosaccharides, as shown below.

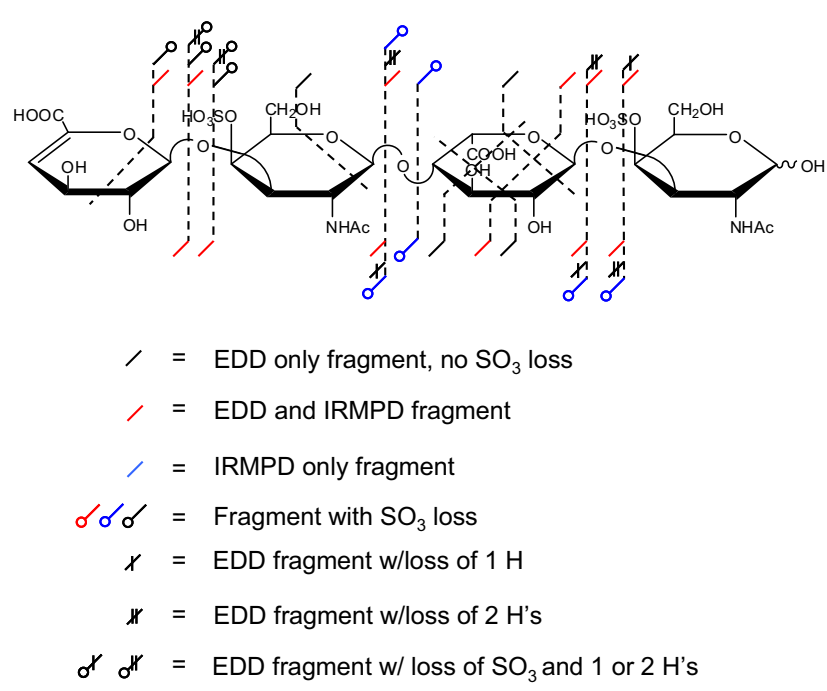

Figure 2. A new fragmentation annotation scheme for showing the products of EDD and IRMPD, applied to the $[\mathrm{M}-2 \mathrm{H}]^{2-}$ precursor ion of $\mathbf{1}$.

\section{EDD of DS dp6, dp8, and dp10}

EDD of the $[\mathrm{M}-3 \mathrm{H}]^{3-}$ of DS dp6, 2, produces the mass spectrum ${ }^{\circ}$ shown $^{\circ}$ in $^{\circ}{ }^{\circ}$ igure 3 . ${ }^{\circ}$ The ${ }^{\circ}$ products $^{\circ}$ observed in the IRMPD mass spectrum of the $[\mathrm{M}-3 \mathrm{H}]^{3-}$ precursor ion of $\mathbf{2}$ are compared with the observed EDD products (peak list and intensities in supplemental data) in the annotated $^{\circ}$ structure $^{\circ}$ shown $^{\circ}$ in $^{\circ}$ Figure $^{\circ} 2$, , inset. $^{\circ}$ EDD $^{\circ}$ of the $[\mathrm{M}-4 \mathrm{H}]^{4-}$ precursor ion of DS dp8, 3, and the $[\mathrm{M}-5 \mathrm{H}]^{5-}$ precursor ion of DS dp4, 4, produces the mass $^{\circ}$ spectra ${ }^{\circ}$ shown $^{\circ}$ in $^{\circ}{ }^{\circ}$ igures ${ }^{\circ} 4^{\circ}$ and $^{\circ} 5,{ }^{\circ}$ respectively. Due to the complexity of the EDD mass spectra of 3 and 4 , the mass scale is divided into three different $\mathrm{m} / \mathrm{z}$ ranges. Products observed in the IRMPD of $[\mathrm{M}-4 \mathrm{H}]^{4-}$ precursor ion of 3 (peak list and intensities in supplemental data) are compared with the observed EDD products of 3 in the annotated structure shown in the inset ${ }^{\circ}$ of $^{\circ}$ Figure $^{\circ} 4 \mathrm{c},{ }^{\circ}$ inset, ${ }^{\circ}$ while ${ }^{\circ}$ the ${ }^{\circ}$ structure ${ }^{\circ}$ in ${ }^{\circ}$ Figure $^{\circ} 6$ compares products of IRMPD (peak list and intensities in supplemental data) and EDD for the $[\mathrm{M}-5 \mathrm{H}]^{5-}$ precursor ion of 4 .

Although the charge reduced species $[\mathrm{M}-3 \mathrm{H}]^{2-\cdot}$ is not observed in the EDD spectrum of 2, the charge reduced species minus $\mathrm{SO}_{3},\left[\mathrm{M}-3 \mathrm{H}-\mathrm{SO}_{3}\right]^{2-}$ is observed. For EDD of 3 and $\mathbf{4}$, both the charge reduced species (labeled with an inverted filled triangle over the peak) and the charge reduced species minus $\mathrm{SO}_{3}$ are observed. EDD produces more extensive fragmentation than IRMPD for 2,3, and 4 , as can be seen in the annotated structures ${ }^{\circ}$ shown $^{\circ}$ as $^{\circ}$ insets ${ }^{\circ}$ to $^{\circ}$ Figure $^{\circ} 3^{\circ}$ and $^{\circ} 4^{\circ}$, and $^{\circ}$ in Figure $^{\circ} 6^{\circ}\left(\mathrm{DS}^{\circ} \mathrm{dp} 10\right),{ }^{\circ}$ respectively. ${ }^{\circ} \mathrm{For}^{\circ} 2$ and $^{\circ} 3$, ${ }^{\circ}$ the ${ }^{\circ}$ small number of products that are observed only in the IRMPD mass spectra but are not observed by EDD are those that result from $\mathrm{SO}_{3}$ loss. For 4, all products observed in the IRMPD spectrum are observed in the EDD spectrum.

EDD of 2, 3, and 4 produces abundant cleavage of glycosidic bonds. In contrast to IRMPD of these com- 


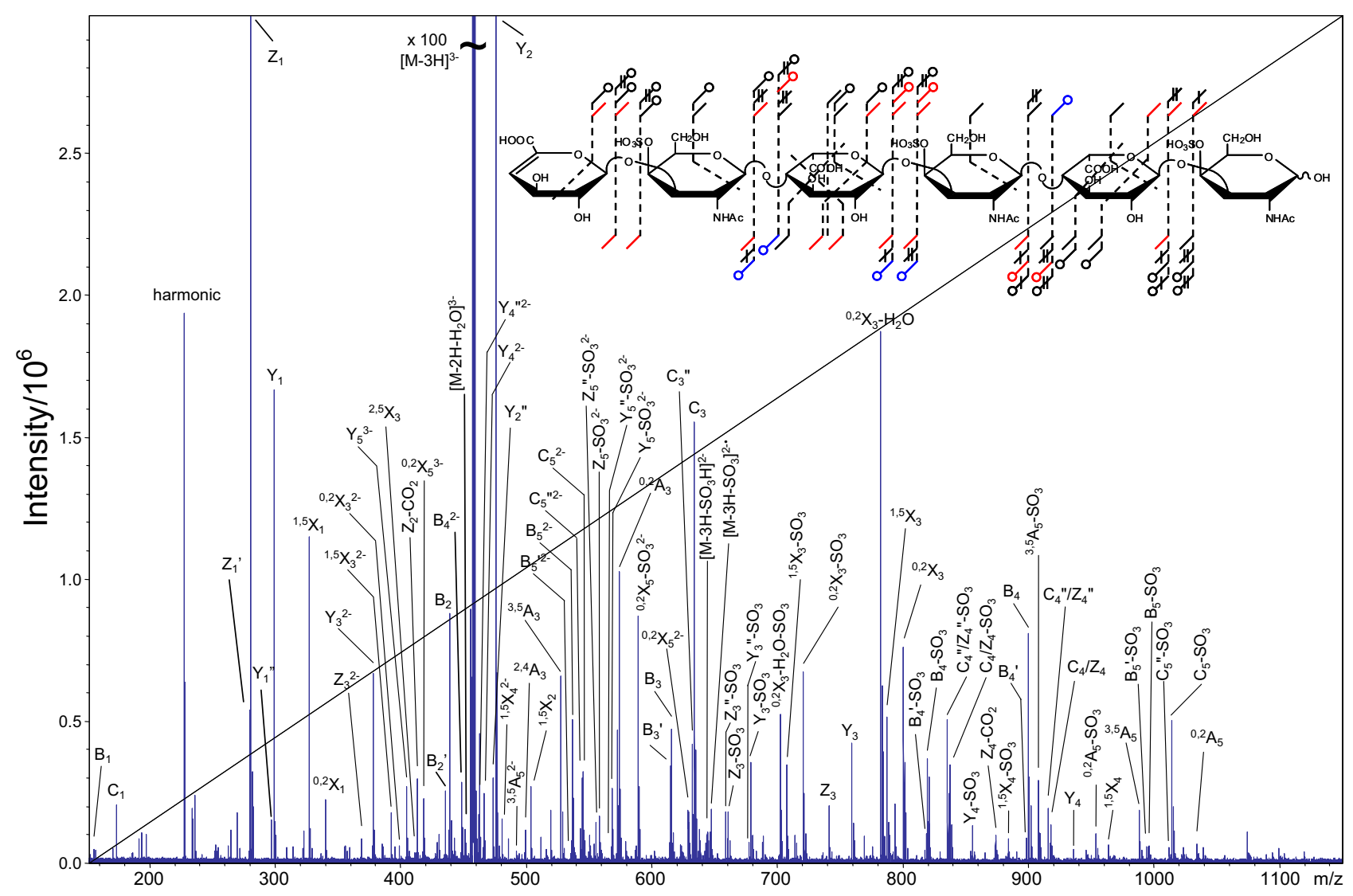

Figure 3. EDD mass spectrum of the $[\mathrm{M}-3 \mathrm{H}]^{3-}$ precursor ion of DS dp6, 2. Inset: Observed product ions from the EDD and IRMPD MS/MS data of 2 combined and annotated using the scheme presented in $^{\circ}$ Figure 2 .

pounds, ${ }^{\circ} \mathrm{EDD}^{\circ}$ cleaves $^{\circ}$ all $^{\circ}$ glycosidic $^{\circ}$ bonds $^{\circ}\left(\right.$ Figures $^{\circ} 3$ and ${ }^{\circ} 4^{\circ}$ insets, ${ }^{\circ}$ and ${ }^{\circ}$ Figure $^{\circ} 6$ ). ${ }^{\circ}$ Because ${ }^{\circ}$ of ${ }^{\circ}$ the ${ }^{\circ}$ symmetry ${ }^{\circ}$ of the oligosaccharides presented in this work, the even numbered $C_{n}$ and $Z_{n}$ glycosidic bond cleavages are isobaric (e.g., $C_{2} / Z_{2}, C_{4} / Z_{4}$, etc.), and cannot be distinguished. We are presently attempting to label the NRE or RE saccharide to allow the assignment of these ambiguous peaks. For all the DS oligosaccharides presented in this work, the isobaric $C_{2}$ and $Z_{2}$ singlycharged products are not assigned as they overlap with the precursor ion. However, for 2 , the $C_{2} / Z_{2}$ glycosidic bond cleavages are observed as the even-electron product $\mathrm{C}_{2} / \mathrm{Z}_{2}-\mathrm{SO}_{3}$ only in the IRMPD spectrum. The even-electron product $\mathrm{C}_{2} / \mathrm{Z}_{2}-\mathrm{SO}_{3}$ is observed in both the EDD and IRMPD mass spectra for 3 and 4.

Some glycosidic bond cleavage products from IRMPD of 2, 3, and 4 are observed only with $\mathrm{SO}_{3}$ loss. While $\mathrm{SO}_{3}$ loss accompanying glycosidic bond cleavage is observed in EDD of 2, 3, and 4, these glycosidic bond cleavages are also observed without $\mathrm{SO}_{3}$ loss, facilitating the easy assignment of these peaks. However, the $Z_{5}$ glycosidic bond cleavage is observed in the EDD mass spectrum of 2 only as the doubly-charged even-electron $\mathrm{Z}_{5}-\mathrm{SO}_{3}$ and $\mathrm{Z}_{5}^{\prime \prime}-\mathrm{SO}_{3}$ product ions, similar to the $\mathrm{Z}_{3}$ fragmentation pattern for 1 . For 3 and $4, Z_{m-1}(m=$ degree of polymerization) is observed in addition to $\mathrm{Z}_{m-1}-\mathrm{SO}_{3}$.

\section{Hydrogen Rearrangement Accompanying Glycosidic Bond Cleavages}

EDD ${ }^{\circ}$ f $1,2,3$, and $^{\circ} 4$ (Figures $2,93,4$, and 5 , respectively) produces several glycosidic bond cleavages that are accompanied by the loss of 1 or $2 \mathrm{H}$ atoms. The annotation for these cleavages are represented with one or two hatch marks bisecting the fragment label on the molecule $^{\circ}\left(\right.$ see $^{\circ}$ Figure $^{\circ} 2^{\circ}$ for $^{\circ}$ annotation ${ }^{\circ}$ scheme), ${ }^{\circ}$ and ${ }^{\circ}$ we $^{\circ}$ refer to these products as $\mathrm{B}_{n}{ }^{\prime}$ and $\mathrm{Z}_{n}{ }^{\prime}$ indicating the loss of one additional hydrogen atom, and $\mathrm{C}_{n}{ }^{\prime \prime}, \mathrm{Z}_{n}{ }^{\prime \prime}$, and $\mathrm{Y}_{n}{ }^{\prime \prime}$ indicating the loss of an additional two hydrogen atoms. Brüll et al. have reported glycosidic bond cleavages with loss of two hydrogen atoms from CAD of native ${ }^{\circ}$ and $^{\circ}$ permethylated ${ }^{\circ}$ oligosaccharides $^{\circ}[40] . .^{\circ}$ They found that only C-type glycosidic cleavages undergo the loss of two hydrogen atoms, and the normal glycosidic bond cleavage products were not observed in the CAD spectrum.

For the EDD work here, conventional glycosidic bond cleavage products are always present when any glycosidic bond cleavage is observed with additional hydrogen atom loss. Unlike products previously observed from EDD of $\mathrm{HS}^{\circ}$ tetrasaccharides ${ }^{\circ}\left[28,{ }^{\circ} 29\right],{ }^{\circ}$ glycosidic $^{\circ}$ bond $^{\circ}$ cleavages with additional hydrogen loss are less intense than the accompanying glycosidic bond cleavage. These hydrogen atom loss satellite peaks are not observed in the IRMPD 

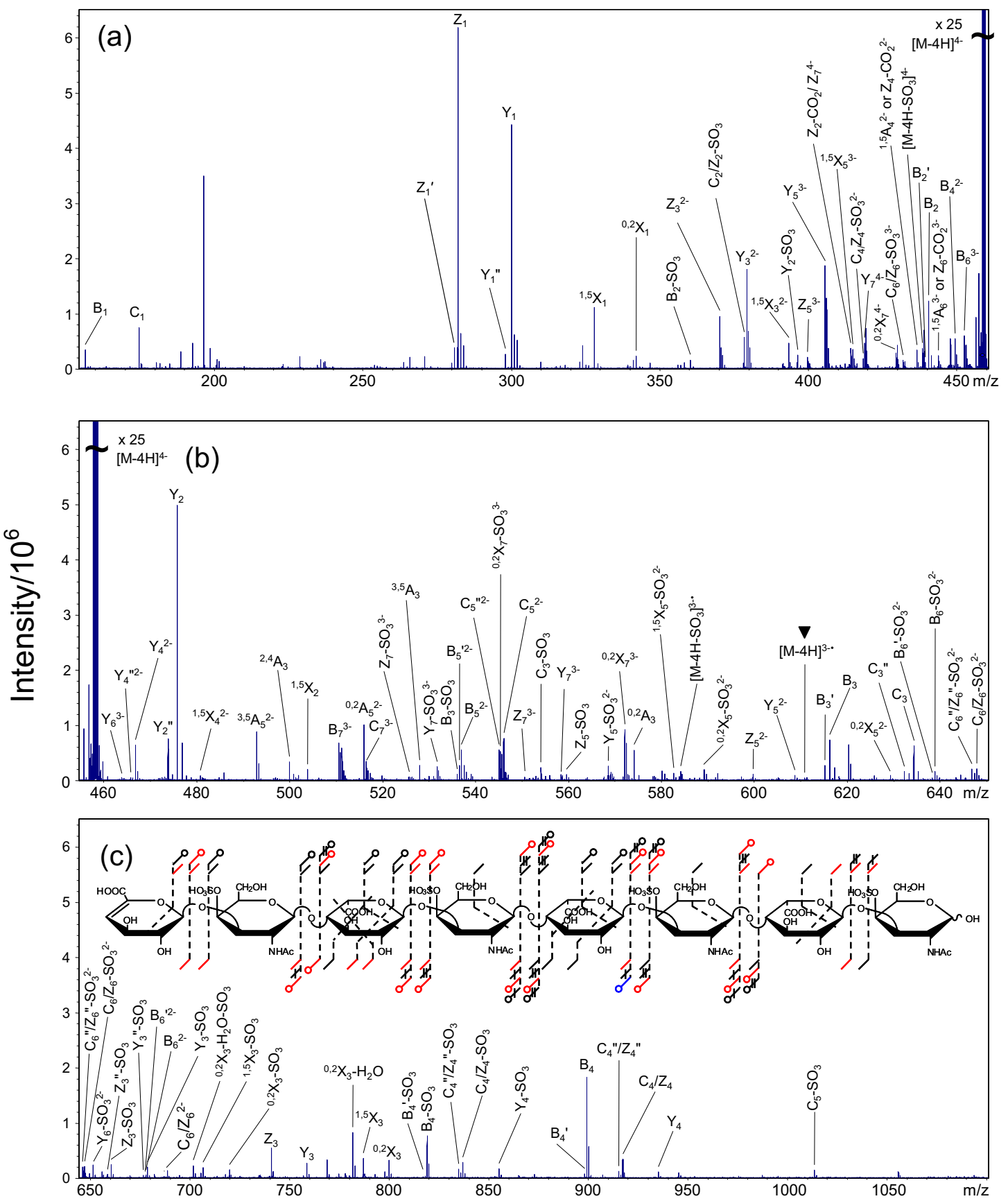

Figure 4. EDD mass spectrum of the $[\mathrm{M}-4 \mathrm{H}]^{4-}$ precursor ion of DS dp8, 3. The mass scale was divided into three regions for clarity. (a) $m / z$ 155-460, (b) $m / z$ 455-650, and (c) $m / z$ 645-1100. Inset: Observed product ions from the EDD and IRMPD MS/MS data of 3 combined and annotated using the ${ }^{\circ}$ scheme $^{\circ}$ presented $^{\circ}$ in ${ }^{\circ}$ Figure $^{\circ} 2 .^{\circ}$ The $^{\circ}$ charge $^{\circ}$ reduced $^{\circ}$ species $^{\circ}$ is ${ }^{\circ}$ indicated ${ }^{\circ}$ with $^{\circ} a^{\circ}$ inverted $^{\circ}$ filled triangle over the peak label.

mass spectra of the DS oligosaccharides, suggesting that these products arise through a radical fragmentation mechanism. In the case of the loss of one additional hydrogen atom, the product ion is odd-electron $\left(\mathrm{B}_{n}{ }^{\prime}\right.$ and $\left.\mathrm{Z}_{n}{ }^{\prime}\right)$, strongly suggesting that the precursor ion was oddelectron. The other unusual glycosidic products are evenelectron $\left(\mathrm{C}_{n}{ }^{\prime \prime}, \mathrm{Z}_{n}{ }^{\prime \prime}\right.$, and $\left.\mathrm{Y}_{n}{ }^{\prime \prime}\right)$.
A number of the features of hydrogen atom loss are evident from the EDD mass spectra of all four compounds. The $Z_{1}$ and $Y_{1}$ are always accompanied by $Z_{1}{ }^{\prime}$ and $\mathrm{Y}_{1}{ }^{\prime \prime}$. Aside from $\mathrm{Z}_{1}{ }^{\prime}$, the $\mathrm{B}_{n}$ cleavages are the only glycosidic cleavages observed with loss of a single hydrogen atom, $\mathrm{B}_{n}{ }^{\prime}$, that is, B-type glycosidic cleavages are not observed with loss of two hydrogen atoms. Also, $\mathrm{Y}_{1}, \mathrm{Y}_{2}$, 

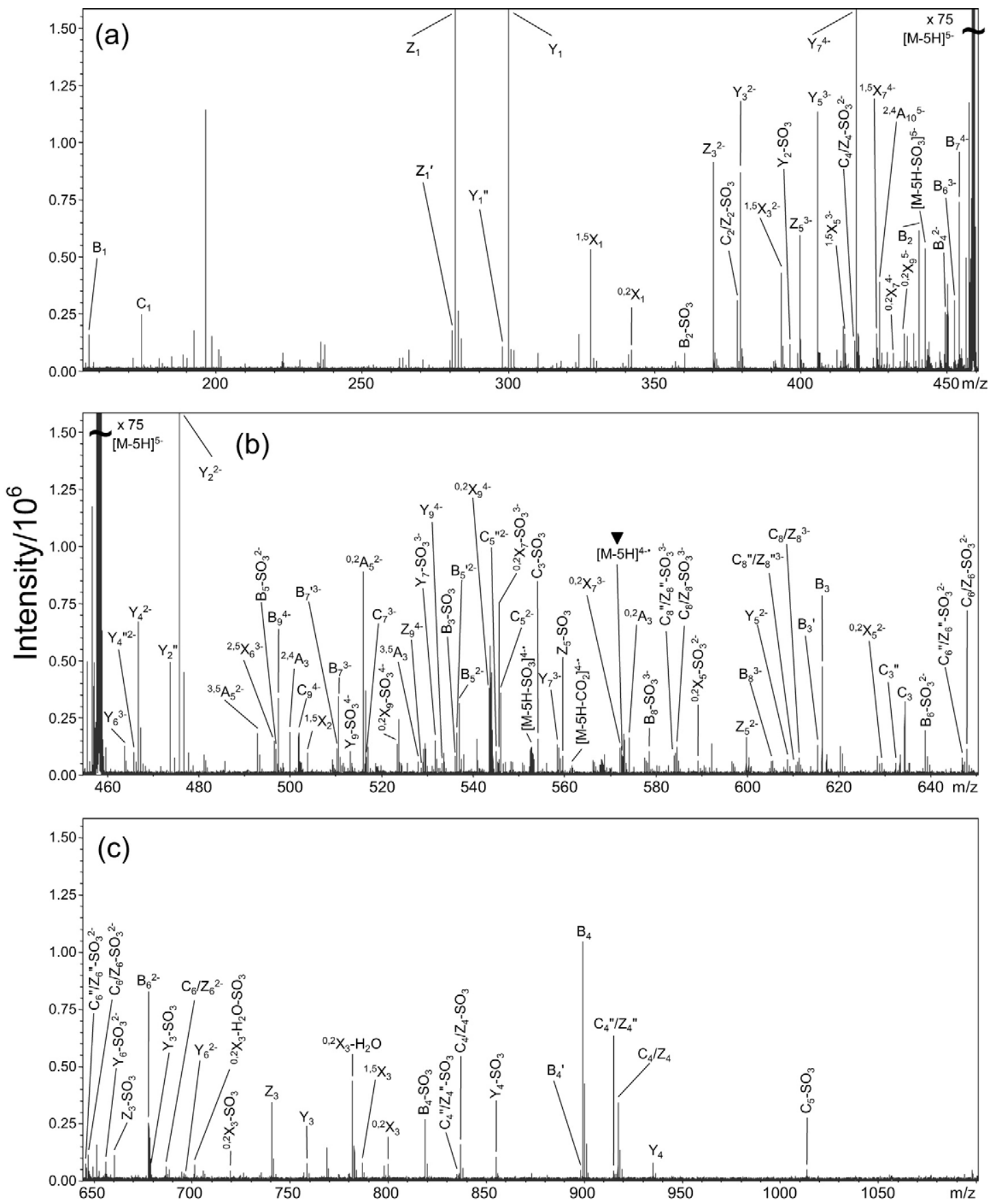

Figure 5. EDD mass spectrum of the $[\mathrm{M}-5 \mathrm{H}]^{5-}$ precursor ion of DS dp10, 4 . The mass scale was divided into three different regions for clarity. (a) $m / z$ 155-460, (b) $m / z$ 455-650, and (c) $m / z$ 645-1100. The charge reduced species is indicated with a inverted filled triangle over the peak label.

and $\mathrm{Y}_{4}$ are the only $\mathrm{Y}$ glycosidic cleavages observed with loss of two hydrogen atoms, $Y_{1}{ }^{\prime \prime}, Y_{2}{ }^{\prime \prime}$, and $Y_{4}{ }^{\prime \prime}$, respectively.

\section{Cross-Ring Cleavages}

Cross-ring fragmentation from EDD of 2 to 4 occurs primarily within the IdoA residues rather than the GalNAc4S residues, similar to EDD of $\mathbf{1}$, and both Aand X-type cleavages are observed. Typically, only A-type cross-ring cleavages are observed in the CAD or
IRMPD mass spectra of oligosaccharide even-electron ions. For example, predominately A-type cross-ring cleavages ${ }^{\circ}$ are $^{\circ}$ observed $^{\circ}$ in $^{\circ} \mathrm{IRMPD}^{\circ}$ of $^{\circ} 2$ to $^{\circ} 4$ (Figure $^{\circ} 6$, and $^{\circ}$ Figures $^{\circ} 3^{\circ}$ and $\left.^{\circ} 4\right) .^{\circ}$ In $^{\circ}{ }^{\circ}$ contrast, ${ }^{\circ}$ EDD $^{\circ}$ of ${ }^{\circ} 2,{ }^{\circ} 3,{ }^{\circ}$ and $^{\circ} 4$ produces abundant $\mathrm{A}$ - and $\mathrm{X}$-type cross-ring cleavages.

${ }^{0,2} X_{n}$ and ${ }^{1,5} X_{n}$ ( $n=$ odd number) cleavages of IdoA residues are found in the EDD mass spectra, but are not observed in IRMPD of 2 to 4 , suggesting fragmentation through a radical mechanism. Only ${ }^{0,2} X_{1}$ is observed in both the EDD and IRMPD mass spectra for 1 to 4 , all 


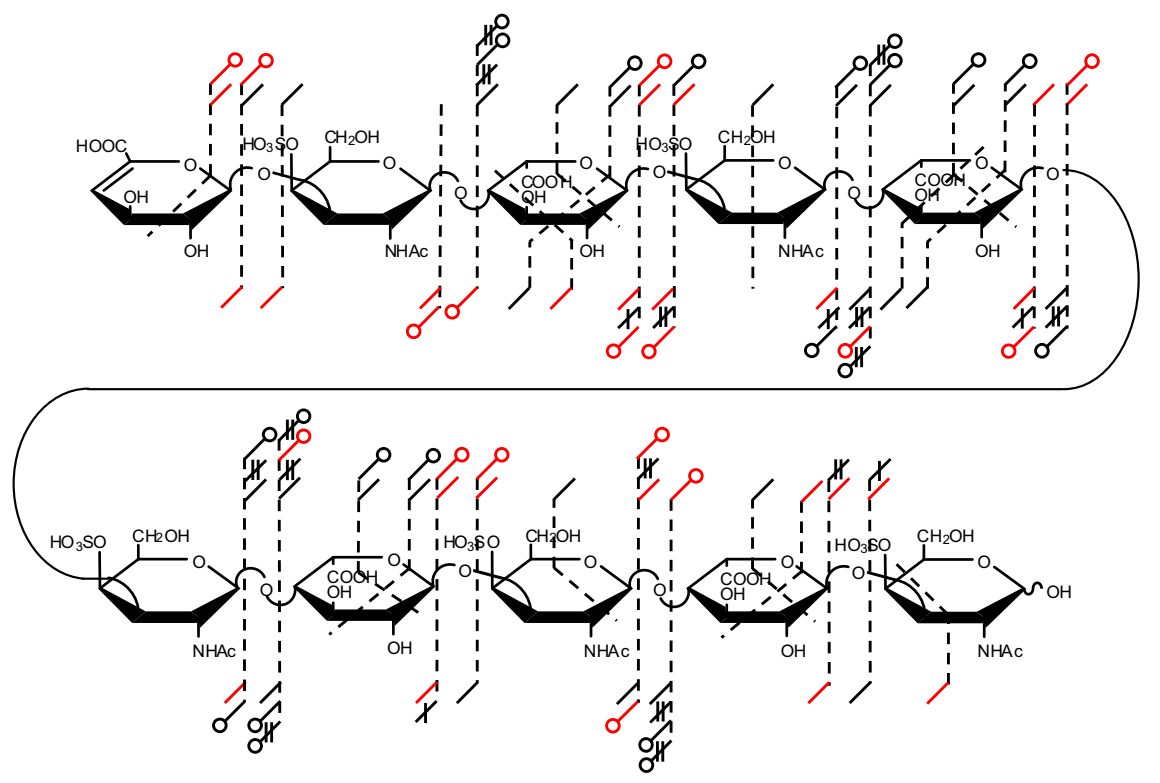

Figure 6. Observed product ions from the EDD and IRMPD MS/MS data of DS dp10, 4, combined and ${ }^{\circ}$ annotated ${ }^{\circ}$ using ${ }^{\circ}$ the ${ }^{\circ}$ scheme $^{\circ}$ presented $^{\circ}$ in ${ }^{\circ}$ Figure $^{\circ} 2$.

other X-products are found only by EDD. Except for the IdoA saccharide next to the RE, these product ions are also observed with $\mathrm{SO}_{3}$ loss. The preference for IdoA to undergo ${ }^{1,5} \mathrm{X}_{n}$ cleavage can be explained by the fragmentation mechanisms proposed in Schemes $\mathbf{1} \mathbf{a}$ and $\mathbf{b}$. A radical site located at the carboxylic acid group on IdoA, formed from either the initial electron detachment or hydrogen rearrangement, may undergo a hydrogen atom rearrangement to create a $\mathrm{C} 2 \mathrm{O}$ radical (Scheme 1a) or a delocalization-stabilized C3 radical (Scheme 1b). Either of these radical products can fragment to form ${ }^{1,5} \mathrm{X}_{n}$ from IdoA. These hydrogen rearrangement fragmentation mechanisms have been proposed to explain the products observed from frag-

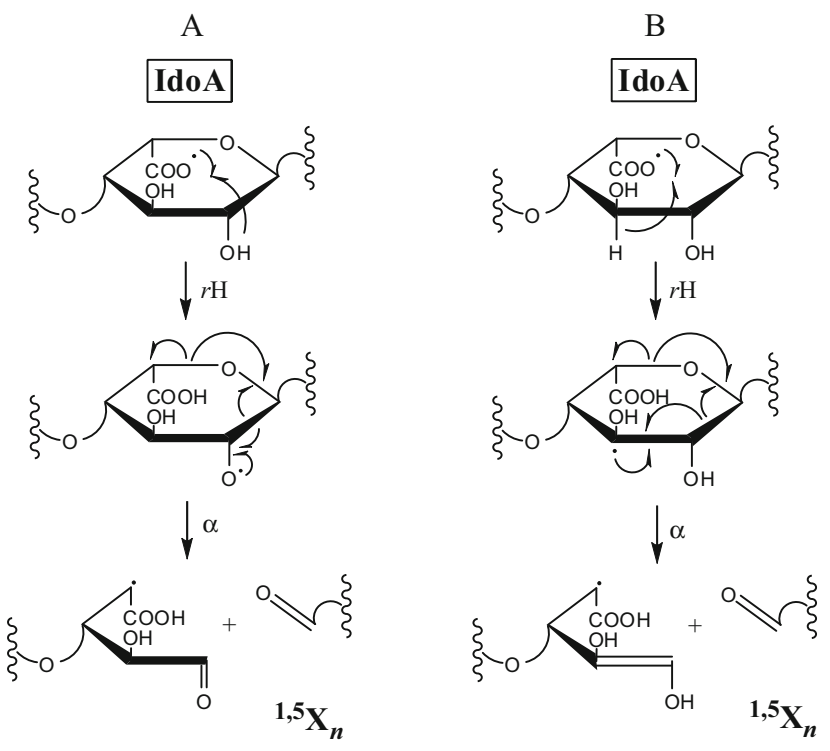

Scheme 1 mentation of the hexuronic acid residues in GAG tetrasaccharides $[28] \cdot{ }^{\circ 1,5} \mathrm{X}_{n}$-type fragmentation is not predicted to occur for the $\triangle \mathrm{UA}$ on the NRE through this proposed mechanism as the double-bond restricts the conformational change necessary to bring the carboxyl radical into the proximity of the $\mathrm{C} 2 \mathrm{OH}$ or $\mathrm{C} 3$ hydrogen for hydrogen atom transfer.

Cross-ring cleavage of the NRE residue of 2,3, and 4 is similar to that observed in EDD of 1 . The ${ }^{0,2} X_{m-1}(m=$ degree of polymerization) cleavage is observed as both an even-electron product with same charge as the precursor ion, and an odd-electron product ion with one less charge than the precursor ion. The odd-electron product is also accompanied by the loss of $\mathrm{SO}_{3}$, forming the odd-electron ${ }^{0,2} \mathrm{X}_{m-1}-\mathrm{SO}_{3}$ product ion.

${ }^{1,5} \mathrm{X}_{n}(n=$ even number) cleavages are also observed for many of the GalNAc4S residues for 1 to 4 , except for the RE GalNAc4S. While ${ }^{1,5} \mathrm{X}_{0}$ cleavage may occur on the RE, the resulting product ion is outside the $\mathrm{m} / \mathrm{z}$ detection range. The preference for GalNAc4S to form the ${ }^{1,5} \mathrm{X}_{n}$ cleavage can be rationalized by the mechanisms proposed in Scheme $\mathbf{2 a}$ and $\mathbf{b}$. A radical site located at the sulfate group on GalNAc4S undergoes hydrogen atom rearrangement to create a C6 (Scheme 2a), or loses $\mathrm{SO}_{3}$ and then undergoes hydrogen atom rearrangement to create a $\mathrm{C}^{\circ}$ (Scheme $\mathbf{2 b}$ ). The C6 species can undergo facile decomposition to form the ${ }^{1,5} \mathrm{X}_{n}$ product.

EDD of 1, 2, and 3 does not produce cross-ring cleavage within the reducing end residue, GalNAc4S. This is in contrast to our previous results obtained with HS tetrasaccharides, for which cross-ring products were observed $^{\circ}$ for ${ }^{\circ}$ the ${ }^{\circ}$ reducing ${ }^{\circ}$ end $^{\circ}$ sugar $^{\circ}[28]^{\circ}{ }^{\circ}$ For $^{\circ}$ EDD $^{\circ}$ of the HS tetrasaccharides, products from cleavage of the reducing end were typically observed in the IRMPD 


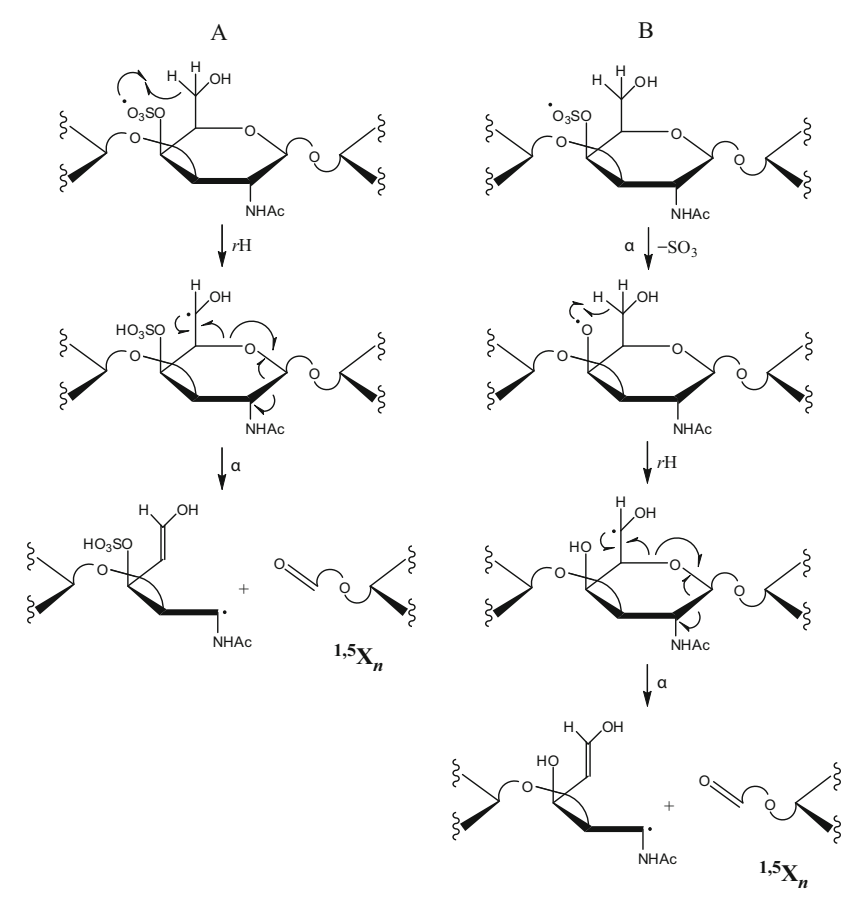

Scheme 2

mass spectra, suggesting formation of these products through a nonradical pathway. As no products from the cleavage of the reducing end are observed in EDD or IRMPD spectra, these data suggest that the reducing end is more stable toward fragmentation for DS oligosaccharides than for HS oligosaccharides, perhaps as a result of the $\beta 1-3$ linkage as opposed to $\beta 1-4$ linkage of the amino sugar.

\section{Product Ion $\mathrm{SO}_{3}$ Loss}

Sulfate is labile under most CAD or IRMPD conditions and readily undergoes the cleavage of the half-ester bond, resulting in the loss of $\mathrm{SO}_{3}$. The extent of $\mathrm{SO}_{3}$ loss is lower in EDD than in IRMPD of 1 to 4 . Generally, EDD product ions that exhibit $\mathrm{SO}_{3}$ loss are accompanied by the related fragments that have retained $\mathrm{SO}_{3}$. Such product ion pairs are easy to identify as they differ by $79.957 \mathrm{u}$. For 2 and 3, the only products that are exclusive to the IRMPD mass spectra result from $\mathrm{SO}_{3}$ loss (shown in blue in the annotation scheme). All products observed by IRMPD of 4 are observed for EDD of 4 . For EDD of 1 and $2, \mathrm{SO}_{3}$ loss from the precursor ion is not observed. For EDD of 3 and $4, \mathrm{SO}_{3}$ loss from the precursor ion is observed as $\left[\mathrm{M}-4 \mathrm{H}-\mathrm{SO}_{3}\right]^{4-}$ and $\left[\mathrm{M}-5 \mathrm{H}-\mathrm{SO}_{3}\right]^{5-}$, respectively. The charge reduced species minus $\mathrm{SO}_{3}$ (e.g., $\left[\mathrm{M}-3 \mathrm{H}-\mathrm{SO}_{3}\right]^{2-}$ for 2, $\left[\mathrm{M}-4 \mathrm{H}-\mathrm{SO}_{3}\right]^{3-\cdot}$ for 3 ) is observed in the EDD spectra of all four DS oligosaccharides studied here.

While several bond cleavages are observed to occur both with and without $\mathrm{SO}_{3}$ loss, no products are observed with loss of two or more equivalents of $\mathrm{SO}_{3}$. For

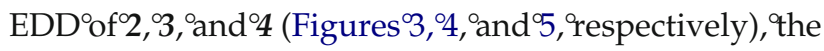
extent of $\mathrm{SO}_{3}$ loss is related to the amount of charge relative to the number of sulfate modifications on the product ion. Our results indicate that if the charge of the product ion is equal to the number of sulfates, no $\mathrm{SO}_{3}$ loss is observed. If the charge of the product ion is less than the number of sulfates, the product ion is typically observed with and without $\mathrm{SO}_{3}$ loss. For example, ${ }^{\circ}$ in $^{\circ}$ EDD $^{\circ}$ of $^{\circ} 2$ (Figure $\left.{ }^{\circ} 3\right)^{\circ}$, the $^{\circ}$ singly-charged peak at $m / z 899.117$ has been assigned as a $B_{4}$ glycosidic cleavage, and contains two sulfate groups. The singlycharged peak at $m / z 819.160$ differs from the $\mathrm{B}_{4}$ product by the exact mass of $\mathrm{SO}_{3}$, and has been assigned as $\mathrm{B}_{4}-$ $\mathrm{SO}_{3}$. The doubly-charged peak at $m / z 440.056$ has also been assigned as a $B_{4}$ product. However, no product ion is present that differs from the doubly-charged $B_{4}$ product by the exact mass of $\mathrm{SO}_{3}$. The relationship of charge state to $\mathrm{SO}_{3}$ loss has been previously observed by $^{\circ} Z_{\text {Zaia }}^{\circ}$ and $^{\circ}$ coworkers $^{\circ}$ for ${ }^{\circ}$ heparin-like ${ }^{\circ}$ molecules ${ }^{\circ}[18]$. During $\mathrm{CAD}, \mathrm{SO}_{3}$ loss can be minimized and glycosidic cleavages maximized if the number of charges on the GAG precursor is equal to the number of sulfate groups, suggesting that protonated form of sulfate is unstable toward $\mathrm{SO}_{3}$ loss. The exception to this observation can be found in the EDD mass spectrum of 2, in which the $\left[\mathrm{Z}_{5}-\mathrm{SO}_{3}\right]^{2-}$ product has no corresponding $\mathrm{Z}_{5}$ fragment. Also, for EDD of 3 and 4, the singlycharged $\mathrm{B}_{3}$ and $\mathrm{C}_{3}$ products, which contain one sulfate, and are accompanied by peaks corresponding to $\mathrm{B}_{3}-$ $\mathrm{SO}_{3}$ and $\mathrm{C}_{3}-\mathrm{SO}_{3}$. These products with $\mathrm{SO}_{3}$ loss are also observed in the IRMPD spectra of these compounds, and are therefore expected in the EDD spectra.

\section{Conclusions}

EDD of GAG oligosaccharides produces glycosidic and cross-ring cleavages at more sites than are observed by IRMPD, presumably as a result of the radical site induced fragmentation processes that can occur by EDD but not by IRMPD. EDD produces predominately evenelectron product ions, although some odd-electron product ions are also observed. EDD products have lower intensity compared with IRMPD products in part because fragmentation is divided among a much large number of mass channels. The large number of glycosidic cleavages permits the determination of the degree of sulfation for each residue, while cross-ring fragmentation can locate the site of sulfation within each residue. Cross-ring cleavages occur predominately on IdoA saccharides. ${ }^{1,5} \mathrm{X}_{n}$ cleavages are observed for most residues except the NRE and RE, and are observed for all IdoA residues. The preference for cross-ring fragmentation of the IdoA residue suggests a radical site on the IdoA residue, either formed initially by EDD, or by hydrogen atom transfer. Also, the stability of the GalNAc4S, evidenced by the small number of observed cross-ring products of GalNAc4S residues may result from the linkage location at C3 instead of C4. EDD produces far fewer product ions observed only with 
$\mathrm{SO}_{3}$ loss compared with IRMPD. For longer oligosaccharides, many EDD products are observed with $\mathrm{SO}_{3}$ loss. Where $\mathrm{SO}_{3}$ loss does occur, fragment pairs separated by the exact mass of $\mathrm{SO}_{3}$ generally occur, facilitating the assignment of these peaks. Overall, the large degree of fragmentation from EDD permits the analysis of sulfated GAG oligosaccharides through a single MS/MS experiment.

\section{Acknowledgments}

The authors gratefully acknowledge financial support from the National Institutes of Health grant no. 2R01-GM038060-16.

\section{References}

1. Perrimon, N.; Bernfield, M. Cellular Functions of Proteoglycans-an Overview. Semin. Cell Dev. Biol. 2001, 12, 65-67.

2. Fannon, M.; Forsten, K. E.; Nugent, M. A. Potentiation and Inhibition of bFGF Binding by Heparin: A Model for Regulation of Cellular Response. Biochemistry 2000, 39, 1434-1445.

3. Wu, Z. L.; Zhang, L.; Yabe, T; Kuberan, B; Beeler, D. L.; Love, A. Rosenberg, R. D. The Involvement of Heparan Sulfate (HS) in FGF1/ HS/FGFR1 Signaling Complex. J. Biol. Chem. 2003, 278, 17121-17129.

4. Sadir, R.; Imberty, A.; Baleux, F.; Lortat-Jacob, H. Heparan Sulfate/ Heparin Oligosaccharides Protect Stromal Cell-derived Factor-1 (SDF1)/CXCL12 against Proteolysis Induced by CD26/Dipeptidyl Peptidase IV. J. Biol. Chem. 2004, 279, 43854-43860.

5. Iozzo, R. V.; San Antonio, J. D. Heparan Sulfate Proteoglycans: Heavy Hitters in the Angiogenesis Arena. J. Clin. Invest. 2001, 108, 349-355.

6. Gotte, M. Syndecans in Inflammation. FASEB J. 2003, 17, 575-591.

7. Batinic, D.; Robey, F. A. The V3 Region of the Envelope Glycoprotein of Human Immunodeficiency Virus Type 1 Binds Sulfated Polysaccharides and CD4-Derived Synthetic Peptides. J. Biol. Chem. 1992, 267, 6664-6671

8. Chen, Y.; Maguire, T.; Hileman, R. E.; Fromm, J. R.; Esko, J. D.; Linhardt, R. J.; Marks, R. M. Dengue Virus Infectivity Depends on Envelope Protein Binding to Target Cell Heparan Sulfate. Nat. Med. 1997, 3, $866-871$.

9. Williams, R. K.; Straus, S. E. Specificity and Affinity of Binding of Herpes Simplex Virus Type 2 Glycoprotein B to Glycosaminoglycans. I. Virol. 1997, 71, 1375-1380

10. Liu, D. F.; Shriver, Z.; Gi, Y. W.; Venkataraman, G.; Sasisekharan, R. Dynamic Regulation of Tumor Growth and Metastasis by Heparan Sulfate Glycosaminoglycans. Semin. Thromb. Hemostat. 2002, 28, 67-78.

11. Chi, L. L.; Amster, J.; Linhardt, R. J. Mass Spectrometry for the Analysis of Highly Charged Sulfated Carbohydrates. Curr. Anal. Chem. 2005, 1, 223-240.

12. Horne, A.; Gettins, P. H-1-NMR Spectral Assignments for Two Series of Heparin-Derived Oligosaccharides. Carbohydr. Res. 1992, 225, 43-57.

13. Takagaki, K.; Kojima, K.; Majima, M.; Nakamura, T.; Kato, I.; Endo, M. Ion-Spray Mass-Spectrometric Analysis of Glycosaminoglycan Oligosaccharides. Glycoconj. J. 1992, 9, 174-179.

14. Juhasz, P.; Biemann, K. Utility of Noncovalent Complexes in the Matrix-Assisted Laser Desorption Ionization Mass Spectrometry of Heparin-Derived Oligosaccharides. Carbohydr. Res. 1995, 270, 131-147.

15. Dai, Y.; Whittal, R. M.; Bridges, C. A.; Isogai, Y.; Hindsgaul, O.; Li, L. Matrix-Assisted Laser Desorption Ionization Mass Spectrometry for the Analysis of Monosulfated Oligosaccharides. Carbohydr. Res. 1997, 304, $1-9$.

16. Lo-Guidice, J.-M.; Herz, H.; Lamblin, G.; Plancke, Y.; Roussel, P.; Lhermitte, M. Structures of Sulfated Oligosaccharides Isolated from the Respiratory Mucins of a Nonsecretor (O, Lea + b-) Patient Suffering from Chronic Bronchitis. Glycoconj. J. 1997, 14, 113-125.

17. Schiller, J.; Arnhold, J.; Benard, S.; Reichl, S.; Arnold, K. Cartilage Degradation by Hyaluronate Lyase and Chondroitin ABC Lyase: A MALDI-TOF Mass Spectrometric Study. Carbohydr. Res. 1999, 318, $116-122$.
18. Zaia, J.; Costello, C. E. Tandem Mass Spectrometry of Sulfated HeparinLike Glycosaminoglycan Oligosaccharides. Anal. Chem. 2003, 75, 2445 2455.

19. Saad, O. M.; Leary, J. A. Compositional Analysis and Quantification of Heparin and Heparan Sulfate by Electrospray Ionization Ion Trap Mass Spectrometry. Anal. Chem. 2003, 75, 2985-2995.

20. Saad, O. M.; Leary, J. A. Heparin Sequencing Using Enzymatic Digestion and ESI-MS with HOST: A Heparin/HS Oligosaccharide Sequencing Tool. Anal. Chem. 2005, 77, 5902-5911.

21. Sweeney, M. D.; Yu, Y.; Leary, J. A. Effects of Sulfate Position on Heparin Octasaccharide Binding to CCL2 Examined by Tandem Mass Spectrometry. J. Am. Soc. Mass Spectrom. 2006, 17, 1114-1119.

22. Zaia, J.; Li, X.-Q.; Chan, S.-Y.; Costello, C. E. Tandem Mass Spectrometric Strategies for Determination of Sulfation Positions and Uronic Acid Epimerization in Chondroitin Sulfate Oligosaccharides. J. Am. Soc. Mass Spectrom. 2003, 14, 1270-1281.

23. Anusiewicz, I.; Jasionowski, M.; Skurski, P.; Simons, J. Backbone and side-chain cleavages in electron detachment dissociation (EDD). J. Phys. Chem. A 2005, 109, 11332.

24. Budnik, B. A.; Haselmann, K. F.; Zubarev, R. A. Electron Detachment Dissociation of Peptide Dianions: An Electron-Hole Recombination Phenomenon. Chem. Phys. Lett. 2001, 342, 299-302.

25. Cooper, H. J.; Hakansson, K.; Marshall, A. G. The Role of Electron Capture Dissociation in Biomolecular Analysis. Mass Spectrom. Rev. 2005, 24, 201

26. Kjeldsen, F.; Silivra, O. A.; Ivonin, I. A.; Haselmann, K. F.; Gorshkov, M. Zubarev, R. A. C $\alpha$-C Backbone Fragmentation Dominates in Electron Detachment Dissociation of Gas-Phase Polypeptide Polyanions. Chem. Eur. J. 11180320051812

27. McFarland, M. A.; Marshall, A. G.; Hendrickson, C. L.; Nilsson, C. L. Fredman, P.; Mansson, J. E. Structural Characterization of the GM1 Ganglioside by Infrared Multiphoton Dissociation/Electron Capture Dissociation, and Electron Detachment Dissociation Electrospray Ionization FT-ICR MS/MS. J. Am. Soc. Mass Spectrom 2005, 16, 752.

28. Wolff, J. J.; Chi, L.; Linhardt, R. J.; Amster, I. J. Electron Detachment Dissociation of Glycosaminoglycan Tetrasaccharides. J. Am. Soc. Mass Spectrom 2007, 18, 234-244.

29. Wolff, J. J.; Chi, L. L.; Linhardt, R. J.; Amster, I. J. Distinguishing Glucuronic from Iduronic Acid in Glycosaminoglycan Tetrasaccharides by Using Electron Detachment Dissociation. Anal. Chem. 2007, 79, 2015-2022.

30. Lortat-Jacob, H.; Turnbull, J. E.; Grimaud, J. A. Molecular-Organization of the Interferon $\gamma$-Binding Domain in Heparan-Sulfate. Biochem. J. 1995, 310, 497-505.

31. Spillmann, D.; Witt, D.; Lindahl, U. Defining the Interleukin-8-Binding Domain of Heparan Sulfate. J. Biol. Chem. 1998, 273, 15487-15493.

32. Stringer, S. E.; Gallagher, J. T. Specific Binding of the Chemokine Platelet Factor 4 to Heparan Sulfate. J. Biol. Chem. 1997, 272, 20508 20514.

33. Tollefsen, D. M.; Sugimori, T.; Maimone, M. M. Effect of Low-Molecular-Weight Heparin Preparations on the Inhibition of Thrombin by Heparin Cofactor-II. Semin. Thromb. Hemost. 1990, 16, 66-70.

34. Maccarana, M.; Casu, B.; Lindahl, U. Minimal Sequence in Heparin Heparan-Sulfate Required for Binding of Basic Fibroblast GrowthFactor. J. Biol. Chem. 1993, 268, 23898-23905.

35. Barzu, T.; Lormeau, J. C.; Petitou, M.; Michelson, S.; Choay, J. HeparinDerived Oligosaccharides-Affinity for Acidic Fibroblast Growth-Factor and Effect on Its Growth-Promoting Activity for Human-Endothelial Cells. J. Cell Physiol. 1989, 140, 538-548.

36. Pervin, A.; Gallo, C.; Jandik, K. A.; Han, X.-J.; Linhardt, R. J. Preparation and Structural Characterization of Large Heparin-Derived Oligosaccharides. Glycobiology 1995, 5, 83-95.

37. Heck, A. J. R.; de Koning, L. J.; Pinkse, F. A.; Nibbering, N. M. M Mass-Specific Selection of Ions in Fourier-Transform Ion Cyclotron Resonance Mass Spectrometry. Unintentional Off-Resonance Cyclotron Excitation of Selected Ions. Rapid Commun. Mass Spectrom. 1991, 5, 406-414.

38. Domon, B.; Costello, C. E. A Systematic Nomenclature for Carbohydrate Fragmentations in FAB-MS/MS Spectra of Glycoconjugates. Glycoconj. J. 1988, 5, 397-409.

39. Saad, O. M.; Leary, J. A. Delineating Mechanisms of Dissociation for Isomeric Heparin Disaccharides Using Isotope Labeling and Ion Trap Tandem Mass Spectrometry. J. Am. Soc. Mass Spectrom. 2004, 15, 1274-1286.

40. Brüll, L. P.; Kovácik, V.; Thomas-Oates, J. E.; Heerma, W.; Haverkamp, J. Sodium-Cationized Oligosaccharides Do Not Appear to Undergo "Internal Residue Loss" Rearrangement Processes on Tandem Mass Spectrometry. Rapid Commun. Mass Spectrom. 1998, 12, 1520-1532. 